\title{
Design and Implementation of IoT based Sensor Module for Real Time Monitoring of Fruit Maturity in Crop Field and in Storage
}

\author{
Nitin Kothari ${ }^{*}$ and Sunil Joshi ${ }^{2}$ \\ CTAE, MPUAT, Udaipur-313001, Rajasthan, India \\ *Corresponding author
}

\section{Keywords}

Maturity Index, Guava fruit, Banana fruit, Papaya fruit, Microcontroller, Sensor, IoT

Article Info

Accepted:

07 February 2019 Available Online: 10 March 2019

\section{A B S T R A C T}

In fruit crops, the ripening of fruit is expressed in terms of change in its physical, physiological \& biochemical parameters. Some of the relevant parameters like Size \& Shape, Colour, Hardness/Softness, Texture etc. can be treated as reference for its maturity. The final stage of fruit ripening is considered to attain a maturity level of these parameters as an indicator for harvesting the fruit crop or ready to use in ripening storage units/chambers. Development of sensor-based maturity indicators can serve as important technological aid to the farmers. The present paper envisages design and implementation of a portable sensor-based prototype for real time monitoring of fruit maturity in crop field and in storage. The sensing parameters in the proposed design are Colour; Softness; surrounding Temperature \& Humidity. An embedded program is developed based on a decision-making algorithm which compares the process values of the sensor output with the reference value of fruit maturity, and the result is displayed and conveyed to the end user. The prototype design is tested for three types of fruits Musa acuminate (Banana'Kela'), Psidium guajava (Gauva-'Amrood'); Carica (papaya-'Papita') and the results are reported in the paper. The proposed design shows $99 \%$ accuracy for all three types of fruits.

\section{Introduction}

The Internet of Things (IoT) is a system of physical devices embedded with sensors and software, interconnected through internet protocol (IP), to perform a task or application with or without human interaction. In agriculture sector, IoT can play an important role for smart farming to collect huge data from sensor and to control the internal processor for efficient farm management. The IoT can also be referred as the interconnection of uniquely identifiable embedded computinglike devices within the existing internet infrastructure $(1,2)$.

The electronic control monitoring units in open farm, greenhouse and in storage unit can be controlled using IoT. Moreover, we can read data from multiple sensors and analyse graphically from anywhere in the world $(3,4)$. IoT authorizes several trends in crop growth monitoring and selection, irrigation decision supports, in Agriculture domain (5). 
The timing of agricultural crop harvesting is an important but crucial decision-making exercise. Crop harvesting at the right stage of crop maturity leads to maximal Harvest Index and hence the yield in terms of increased reproduction efficiency, and a good market value. However, the decision-making exercise is based on manual physical inspection, and many a times, harvesting is done at a prematured stage and sometimes at an over matured stage. In both the cases the overall crop yield is adversely affected. The technology intervention in sensing the maturity indices of the specific crop and subsequent development of IoT based prognostic tools can enhance the accuracy of timings of harvesting and thus, can reduce the possibility of untimely harvesting. Therefore, development of sensor-based maturity indicators can serve as important technological aids to the farmers.

\section{Materials and Methods}

\section{System model}

Figure 1(a) and (b) shows system model and circuit layout of the proposed design respectively. The fruit under test is kept approximately $5 \mathrm{~cm}$ away from the sensor module. The circuit operation is controlled with microcontroller Arduino mega 2560.

The sensor DHT11 is used to sense the real time temperature and humidity. The analog output of the sensor is converted into digital format is supplied to the microcontroller. The temperature range of sensor is typically $0^{\circ} \mathrm{C}$ to $55^{\circ} \mathrm{C}$ and humidity range up to $85 \%$.

An ultrasonic sensor HC SR-04 is used to sense the hardness/softness of the fruit. The sensor output is given in the form of frequency which is calibrated into degree of hardness/softness by computing attenuation coefficient and subsequently programmed in the microcontroller. A colour sensor TCS3200 is used to sense the R,G,B value of the fruit surface. The sensor output is obtained in the form of frequency corresponding to $R, G, B$ values. These $R, G, B$ frequencies are calibrated and programmed in the microcontroller to give resultant colour of the fruit.

All outputs are displayed on LCD display $16 \times 2$ or can also be interfaced with a PC using USB cable. The reference values of the fruit maturity are stored in the memory of the controller. A real time value of sensor output is compared with the reference maturity value and using a decision algorithm or final verdict is displayed regarding the maturity stage of fruit. The sensor data as well as decision on maturity stage of the fruit are sent to GSM SIM 900 module for peer-to-peer connectivity (6). These interfaces are shared on cloud Things peak for the farm management application.

\section{Results and Discussion}

The sensor data of Guava fruits of different maturity levels are measured and indicated in Table 1 . The stage IV is considered as fruit ripening stage. The $R, G, B$ sensor output and ultrasonic sensor output for all IV stages reveals that output frequency decrease with maturity level from stage I through final ripening (Stage IV). The figure 2 shows comparison of R,G,B sensor output for all maturity stages. The reference maturity level is shown by dashed line. Which is equivalent to final ripening stage IV of the fruit.

Figure 3(a) shows the ultrasonic sensor output for all IV stage of Guava fruit and Figure 3(b) shows the corresponding computed attenuation coefficient for all four maturity stages. The dashed line shown in the graph indicates the corresponding value of the fruit ripening stage. 
The decision-making algorithm compares the process value of the sensor output with the reference value stored in microcontroller memory. Based on the comparison the decision is displayed on the screen whether the fruit is ready or not.
When the experiment is carried out the process value of surrounding atmospheric temperature and the value of humidity are measured through DHT11 Temperature and humidity sensor and displayed on the screen. Temperature is very important parameter for the fruit ripening process (7).

Table.1 Sensor data for Guava fruit

\begin{tabular}{|c|c|c|c|c|c|}
\hline \multicolumn{2}{|c|}{ Guava Fruit Parameter } & Maturity stage - I & Maturity stage-II & Maturity stage-III & Maturity stages-IV \\
\hline \multicolumn{2}{|l|}{ Skin color } & Dark green & Light green & Yellowish green & Light yellow \\
\hline \multirow{3}{*}{$\begin{array}{l}\text { Color sensor } \\
\text { output } \\
\text { frequency } \\
(\mathrm{Hz})\end{array}$} & $\mathrm{R}$ & 115.877 & 106.571 & 92.142 & 60.2857 \\
\hline & $\mathrm{G}$ & 141.28 & 133.428 & 120.285 & 87.857 \\
\hline & B & 166.142 & 160.8571 & 151.57 & 115.142 \\
\hline \multicolumn{2}{|c|}{$\begin{array}{l}\text { Received ultrasonic } \\
\text { sensor frequency }\end{array}$} & 4247 & 2880 & 2776 & 2750 \\
\hline \multicolumn{2}{|l|}{$\begin{array}{l}\text { Attenuation } \\
\text { coefficient }\end{array}$} & 2123 & 1440 & 1375 & 1209 \\
\hline
\end{tabular}

Table.2 Sensor data for Banana fruit

\begin{tabular}{|c|c|c|c|c|c|}
\hline $\begin{array}{l}\text { Banana Fruit } \\
\text { Parameter }\end{array}$ & Maturity stage - I & Maturity stage-II & Maturity stage-III & Maturity stages-IV & Maturity stages- $\mathrm{V}$ \\
\hline Color & All green & $\begin{array}{l}\text { Green with trace } \\
\text { of yellow }\end{array}$ & $\begin{array}{l}\text { More yellow than } \\
\text { green }\end{array}$ & $\begin{array}{l}\text { Yellow with a trace } \\
\text { of green }\end{array}$ & All Yellow \\
\hline \multirow{3}{*}{$\begin{array}{l}\text { Colour } \\
\text { sensor } \\
\text { output } \\
\text { frequency } \\
(\mathrm{Hz})\end{array}$} & 285 & 69.85 & 47.42 & 47.17 & 44.42 \\
\hline & 138 & 82.28 & 68.57 & 60 & 58 \\
\hline & 133 & 110.14 & 95.42 & 85.14 & 81.28 \\
\hline $\begin{array}{l}\text { Received } \\
\text { ultrasonic } \\
\text { sensor } \\
\text { frequency }\end{array}$ & 3891.05 & 3984.06 & 2770.08 & 2724.79 & 2645.5 \\
\hline $\begin{array}{l}\text { Attenuation } \\
\text { coefficient }\end{array}$ & 1945.25 & 1992.03 & 1385.39 & 1326.04 & 1302 \\
\hline
\end{tabular}


Table.3 Sensor data for papaya fruit

\begin{tabular}{|c|c|c|c|c|c|}
\hline \multicolumn{2}{|l|}{ Papaya Fruit Parameter } & Maturity stage-I & Maturity stage-II & Maturity stage-III & Maturity stage-IV \\
\hline \multicolumn{2}{|l|}{ Color } & Mature Green & $\begin{array}{c}\text { Breaker } \\
\text { (Green with light } \\
\text { yellow stripe) }\end{array}$ & $\begin{array}{l}\text { 30\% ripe } \\
\text { (orange color stripe with } \\
\text { some light green area) }\end{array}$ & $\begin{array}{c}80 \% \text { ripe } \\
\text { (one and more } \\
\text { orange color stripe) }\end{array}$ \\
\hline \multirow{3}{*}{$\begin{array}{l}\text { Color sensor output } \\
\text { frequency }(\mathrm{Hz})\end{array}$} & $\mathrm{R}$ & 127 & 90 & 62 & 44 \\
\hline & G & 181 & 121 & 100 & 88 \\
\hline & $\mathrm{B}$ & 191 & 141 & 121 & 118 \\
\hline \multicolumn{2}{|c|}{$\begin{array}{l}\text { Received ultrasonic sensor } \\
\text { frequency }\end{array}$} & 3719.35 & 3614.82 & 3542.795 & 3411.98 \\
\hline \multicolumn{2}{|l|}{ Attenuation coefficient } & 1859.675 & 1807.41 & 1771.14 & 1771.14 \\
\hline
\end{tabular}

Fig.1a\&b
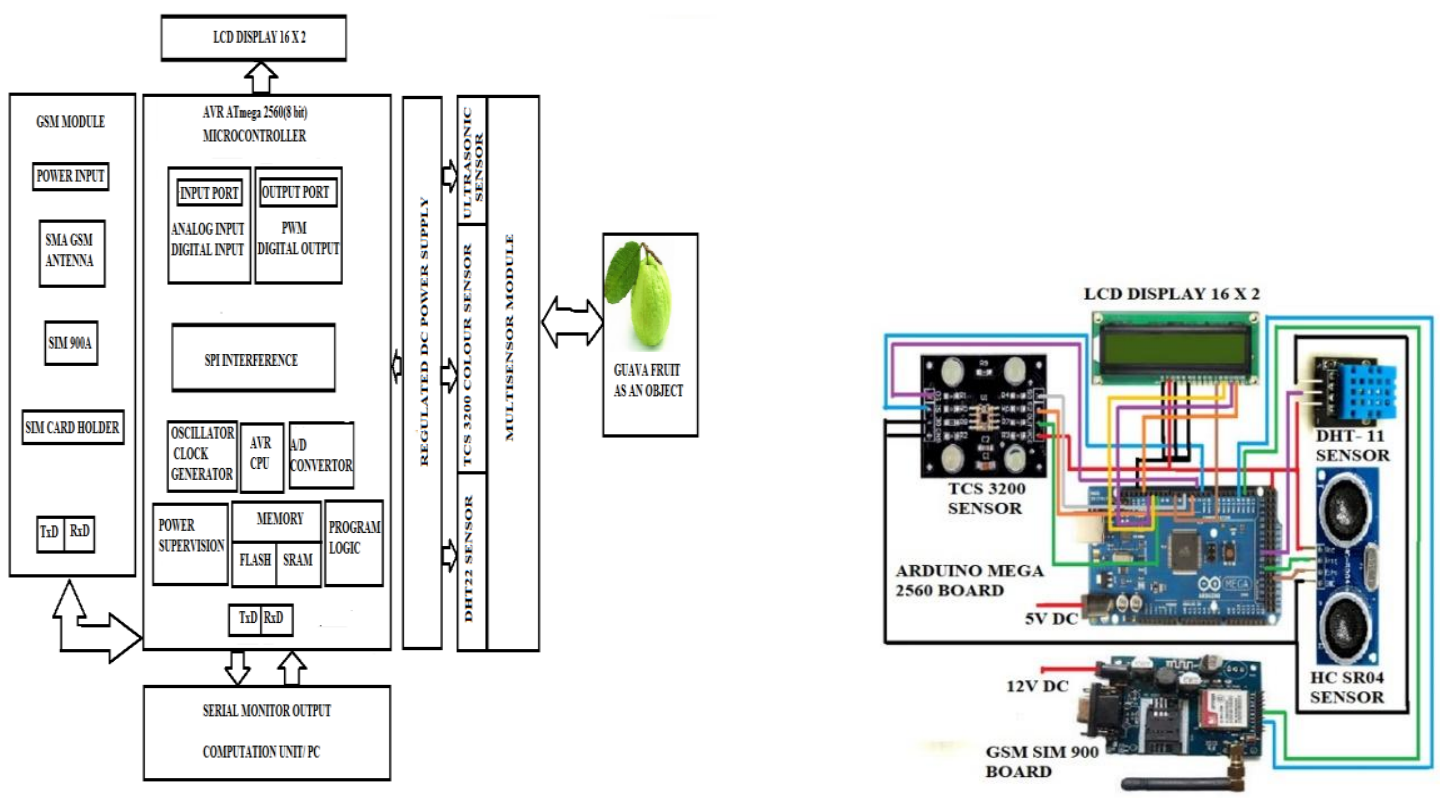

Fig.2 R, G, B sensor data for Guava Fruit
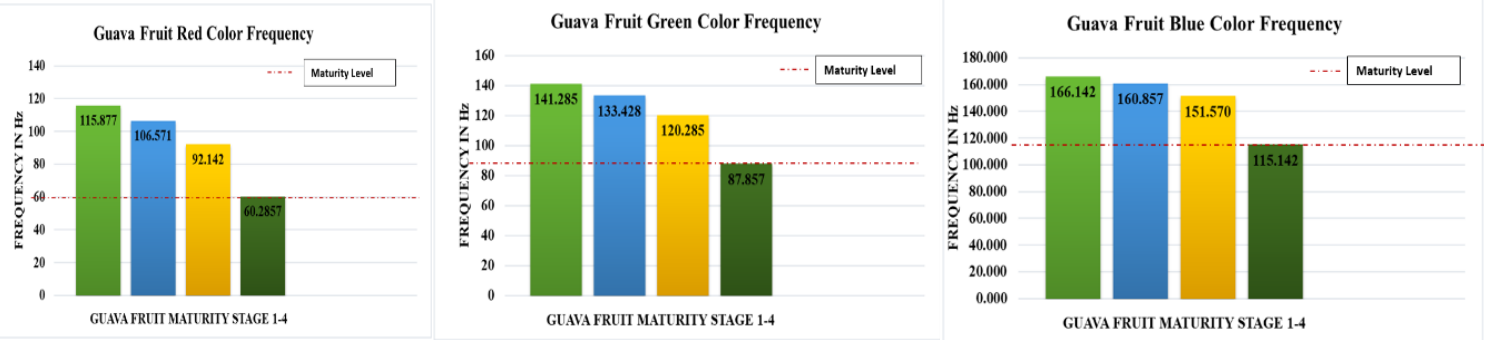
Fig.3 Ultrasonic sensor data for frequency (b) computed value of attenuation coefficient of fig 3(a)

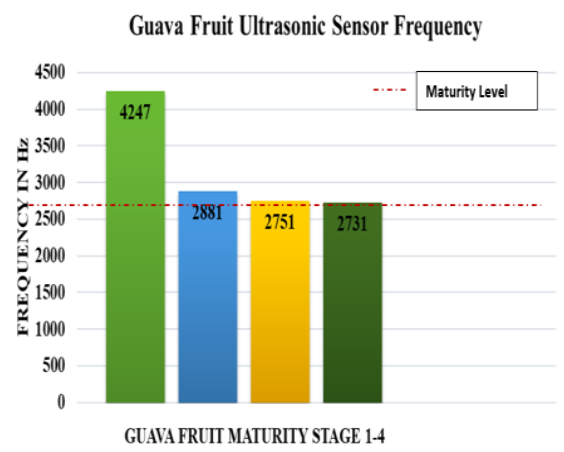

(a)

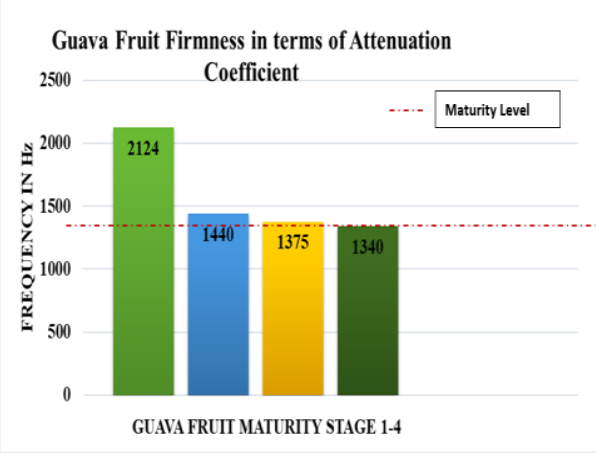

(b)

Fig.4 R, G, B sensor data for Banana Fruit
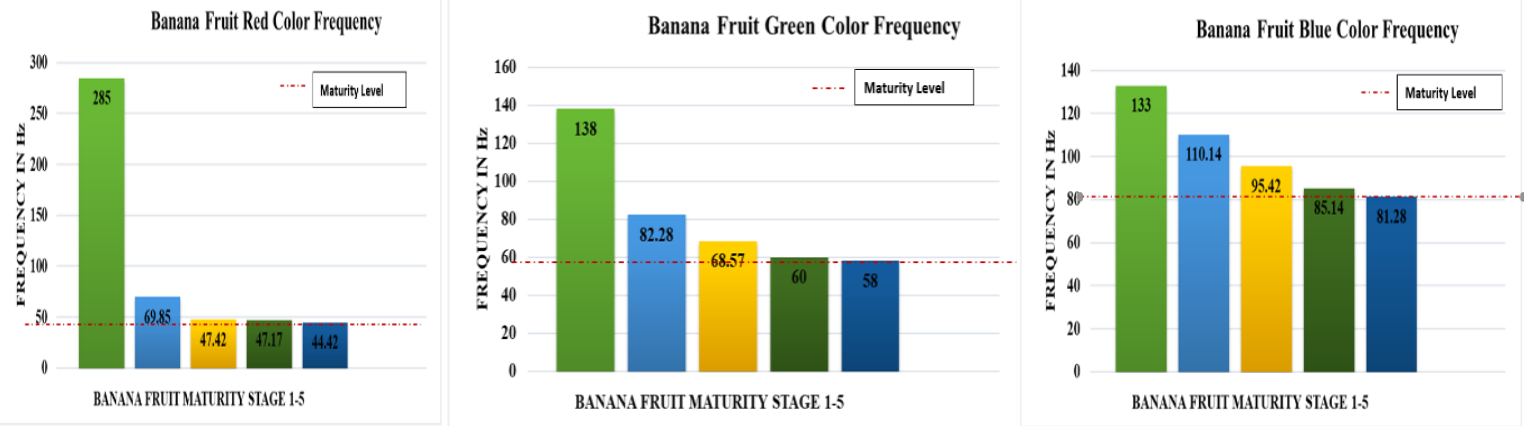

Fig.5 (a) Ultrasonic sensor data for frequency (b) computed value of attenuation coefficient of fig 5(a)

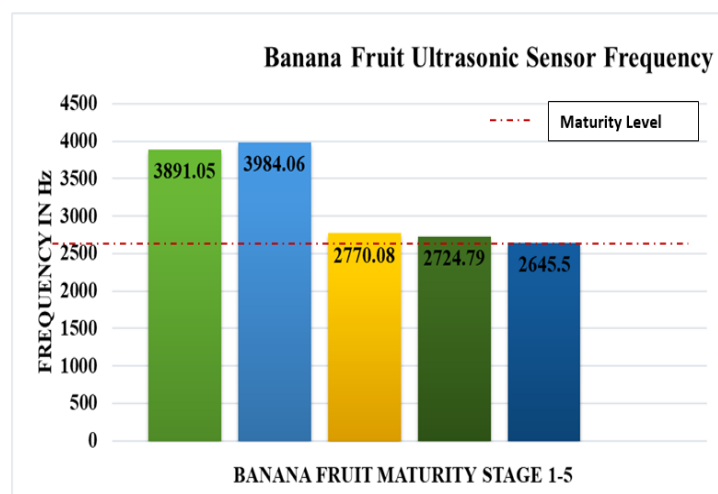

(a)

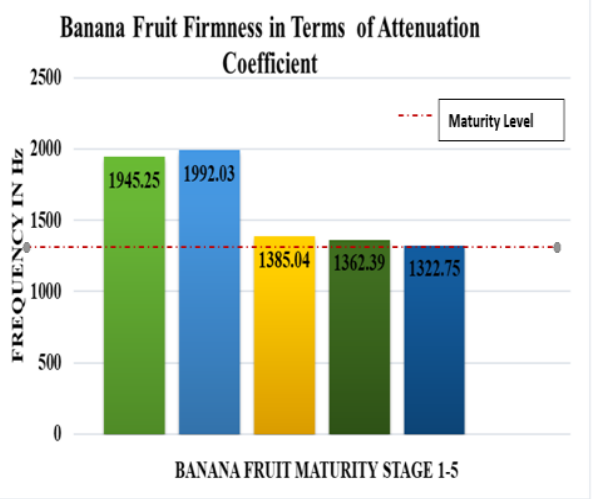

(b) 
Figure.6 R, G, B sensor data for Papaya Fruit
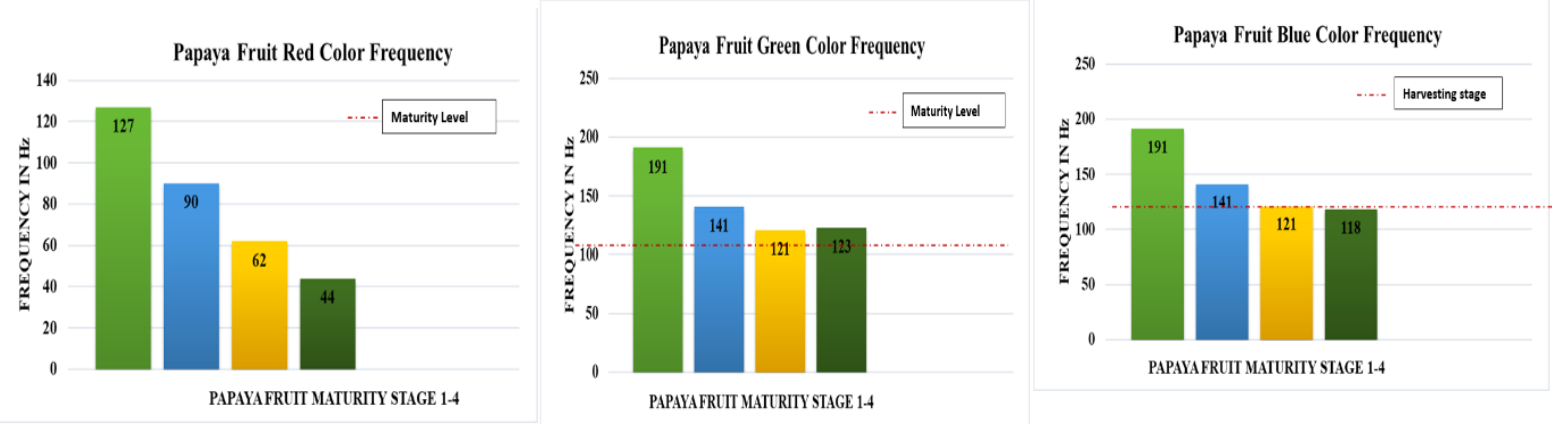

Figure.7(a) Ultrasonic sensor data for frequency (b) computed value of attenuation coefficient of fig 6(a)

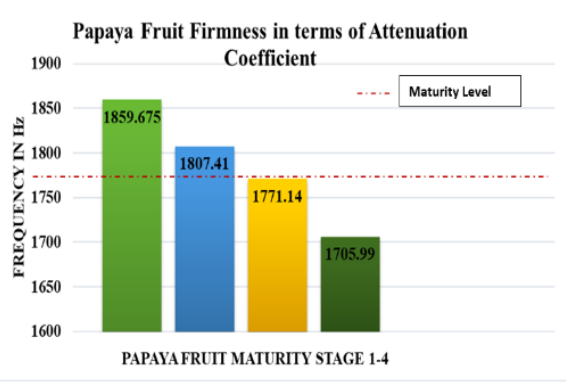

(a)

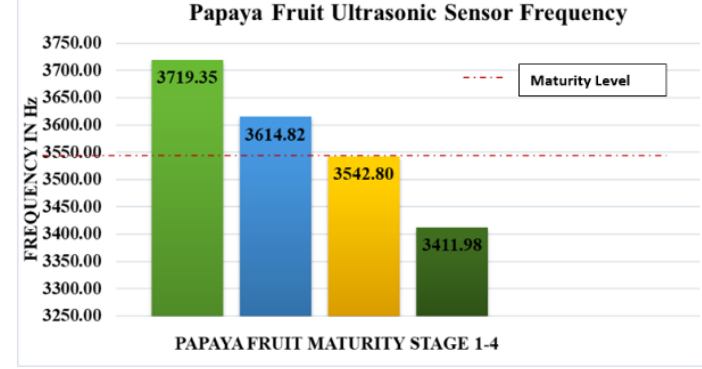

(b)
The sensor data of banana fruits of different maturity levels are measured and indicated in Table 2. The stage $\mathrm{V}$ is considered as fruit ripening stage $(8,9)$. The $R, G, B$ sensor output and ultrasonic sensor output for all $\mathrm{V}$ stages reveals that output frequency decrease with maturity level from stage I through final ripening (Stage V). The figure 4 shows comparison of R, G, B sensor output for all maturity stages. The reference maturity level is shown by dashed line, which is equivalent to final ripening stage $\mathrm{V}$ of the fruit.

Figure 5(a) shows the ultrasonic sensor output for all V stage of Banana fruit and Figure 5(b) shows the corresponding computed attenuation coefficient for all four maturity stages. The dashed line shown in the graph indicates the corresponding value of the fruit ripening stage.

The decision-making algorithm compares the process value of the sensor output with the reference value stored in microcontroller memory. Based on the comparison the decision is displayed on the screen whether the fruit is ready or not.

The sensor data of papaya fruits of different maturity levels are measured and indicated in Table 3. The stage IV is considered as fruit ripening stage (10). The $R, G, B$ sensor output and ultrasonic sensor output for all IV stages reveals that output frequency decrease with maturity level from stage I through final ripening (Stage IV). The figure 6 shows comparison of $\mathrm{R}, \mathrm{G}, \mathrm{B}$ sensor output for all maturity stages. The reference maturity level is shown by dashed line, which is equivalent to final ripening stage $\mathrm{V}$ of the fruit. Figure 7(a) shows the ultrasonic sensor output for all IV stages of papaya fruit and Figure 7(b) shows the corresponding computed attenuation coefficient for all four maturity stages. The dashed line shown in the graph indicates the corresponding value of the fruit ripening stage. 
The decision-making algorithm compares the process value of the sensor output with the reference value stored in microcontroller memory. Based on the comparison the decision is displayed on the screen whether the fruit is ready or not.

In conclusion, a portable multisensory module is designed and implemented to sense and display the maturity status of fruits on the tree or in the artificial ripening units. The maturity data of the fruits are interfaced with cloud through embedded technique. The result of three fruits(Banana- 'Kela'), Psidium guajava (Gauva-'Amrood'); Carica (papaya-' Papita') have shown more than 95 percent accuracy. The prototype can also be used for other fruit crops.

\section{References}

1. From the Internet of computer to the Internet of Things Mattern, Friedemann, Floerkemeier, Christian, Informatikspektrum, 2010, 33(2): 107-121

2. Smart Farming Using IoT, Hariharr C Punjabi, Sanket Agarwal, Vivek Khithani and Venkatesh Muddaliar, International Journal of Electronics and Communication Engineering and Technology (IJECET), Volume 8, Issue 1, January - February 2017, pp. 58-66, Article ID: IJECET_08_01_007.

3. OjasSavale, Anup Managave, Deepika Ambekar, Sushmita Sathe, Internet of Things in Precision Agriculture using Wireless Sensor Networks, International Journal of Advanced Engineering \& Innovative Technology (IJAEIT), Volume 2, Issue 3, December -2015
4. Internet of things: wireless sensor network, International Electrotechnical Commission, White paper.

5.Application of IoT in monitoring and controlling agricultural production", Dusan Markovic, RankoKoprivica, UrosPesovic, Sinisa Ranđic, Acta Agriculturae Serbica, Vol. XX, 40 (2015) 145-153

6. Internet of Things Based Architecture of Web and Smart Home Interface Using GSM", S. Pandikumar, R.S. Vetrivel, International Journal of Innovative Research in Science, Engineering and Technology, ISSN (Print): 2347 - 6710,Volume 3, Special Issue 3, March 2014.

7. Effect of Temperature in color changes of Green vegetable", E. Manolopoulou and T. Varzakas, current research in Nutriition and Food Science, Vol. 4(2), 10-17,2016

8. Stuy of Advanced Maturity Stages of Banana", Tapre A.R. and Jain R.K., International Journal of Advanced Engineering Research and Studies, EISSN2249-8974IJAERS/Vol. I/ Issue III/April-June 2012/272-274.

9. Assessment of banana fruit maturity by image processing technique", D. Surya Prabha and J. Satheesh Kumar, Springer Journal of food science and Technology, 2015 Mar; 52(3): 1316-1327, PMID: 25745200

10. Effect of maturity stage of Papaya Maradol on Physiological and Biochemical Parameters", Laura E. Gayosso-Garcia Sancho, Elhadi M. Yahia, American journal of Agriculture and Biological Science,5(2):194-203,2010.

\section{How to cite this article:}

Nitin Kothari and Sunil Joshi. 2019. Design and Implementation of IoT based Sensor Module for Real Time Monitoring of Fruit Maturity in Crop Field and in Storage. Int.J.Curr.Microbiol.App.Sci. 8(03): 582-588. doi: https://doi.org/10.20546/ijcmas.2019.803.071 